\title{
Ajeno a la Modernidad: La racionalización de la discriminación
}

\author{
Alien to Modernity: The Rationalization of Discrimination \\ Alheio à Modernidade: Racionalização da discriminação
}

\section{Jean Franco}

COLUMBIA UNIVERSITY, ESTADOS UNIDOS

Profesora Emérita de Columbia University, Nueva York. Autora de The Modern

Culture of Latin America (Penguin Books, 1967), César Vallejo. The

Dialectics of Poetry and Silence (Cambridge University Press, 1976), An

Introduction to Latin American Literature (Cambridge University Press,

1969), Plotting Women. Gender and Representation in Mexico (Columbia

University Press, 1989), Marcar diferencias/Cruzar Fronteras (Cuarto

Propio, 1996), The Decline and Fall of the Lettered City: Latin America

and the Cold War (Harvard University Press, 2001) y Cruel Modernity

(Duke University Press, 2013). Correo electrónico:jf29@columbia.edu

Traducción de Félix Ceballos (Profesional en filología e idiomas-Inglés, Universidad Nacional de Colombia, Postulante a Maestro en Literatura Pontificia Universidad Javeriana. Profesor de inglés en el Proyecto de Internacionalización-Explora un Mundo (2013-2014), Unidad de Extensión de lenguas extranjeras, Departamento de Lenguas extranjeras, Facultad de Ciencias Humanas (2013-presente), Universidad Nacional de Colombia. Ha realizado numerosas traducciones en literatura, estudios lingüísticos y análisis del discurso. Correo electrónico: flixceballos@gmail.com

Ensayo

Una versión anterior de este artículo se presentó en la "Cátedra Stanley y Joan Pierson 2006" del Departamento de Historia de la Universidad de Oregón en Febrero 17 de 2006. Versión original titulada "Alien to Modernity': The Rationalization of Discrimination", en A contracorriente Vol. 3, No. 3, Spring 2006, 1-16. Documento accesible en línea desde la siguiente dirección: http://revistas.javeriana.edu.co

doi: 10.11144/Javeriana.cl19-38.amrd

\section{Cómo citar este ensayo:}

Franco,Jean. "Ajeno a la Modernidad: la racionalización de la discriminación". Cuadernos de Literatura 19.38 (2015): 17-33. http://dx.doi.org/10.11144/Javeriana.cl19-38.amrd 
En LA InTRODUCGIón al reporte de la Comisión Peruana de reconciliación y verdad, publicado en 2003, Salomón Lerner, presidente de la misma en su momento, deja ver su disgusto con respecto a la historia de discriminación en su país. Acusa al ejército y a la fuerza pública por un lado y a la insurgencia por el otro, de cometer atrocidades y masacres durante la Guerra Civil de la década de 1980 y comienzos de 1990 en la cual se estima que unas 69.0oo personas fueron asesinadas o desaparecieron y miles fueron forzados a abandonar la región sur-central de sierra. Tres de cada cuatro víctimas, señaló, eran campesinos que tenían por lengua madre el Quechua. Aunque se niega que la guerra haya sido un conflicto étnico, Lerner escribió que

[...] estas dos décadas de destrucción y muerte no hubieran sido posibles sin un profundo desdén hacia las poblaciones desposeídas del país. Un desprecio igualmente expresado por los insurgentes del Sendero Luminoso y por el ejército, un desprecio que se encuentra enquistado en la totalidad de la cotidianidad peruana.

Del lado de Sendero, el exterminio de comunidades enteras se justificó como medio estratégico para un fin específico. Como el régimen Pol Pot en Camboya, Sendero buscó destruir la infraestructura de la sociedad del momento bajo el liderazgo de intelectuales y la construcción desde cero de la misma, atomizando lealtades comunitarias en el proceso. Lo que resulta de interés en este texto es el lenguaje y el discurso discriminatorio, no solo en su manifestación más obvia como insulto degradante, sino también como 'sentido común' y como filosofía política.

En referencia a un archivo de 16.000 testimonios de abuso en la Guerra Civil peruana, Salomón Lerner llama la atención acerca del hecho de que:

[...] una y otra vez, es el insulto racial, el ataque verbal a la gente humilde el que actúa como una contención que precede a las golpizas, las violaciones, los secuestros de hijos e hijas, el tiro de gracia de un agente armado de las fuerzas armadas o la policía ${ }^{1}$.

El insulto es un acto de habla performativo, uno en el que el discurso lleva a cabo una acción, en este caso, la expulsión de la humanidad y todo lo que esto implica. Así lo denuncia la Comisión Guatemalteca de Esclarecimiento Histórico en la documentación de la masacre de miles de indígenas Mayas:

$1 \quad$ El reporte de la Comisión se encuentra en: http://www.cverdad.or.pe. 
El racismo, desde la perspectiva del ejército, justificó equivalencia entre indígenas e insurgentes y generó la creencia de que eran distintos, inferiores, y poco menos que humanos, ajenos al universo moral de los perpetradores, haciendo su eliminación menos problemática. (Grandin 2005)

Lo que es notable de la Comisión Peruana de Reconciliación y Verdad, y que fue designada por el presidente provisional Valentín Paniagua inmediatamente después de la salida de Fujimori del Perú, es que se hace énfasis en un escándalo poco investigado pero que viene de siglos atrás al señalarse el sentimiento de exclusión y diferencia experimentados por la gente y las comunidades victimizadas en los conflictos armados, también al hecho de que "para los centros de poder político y económico lo que ocurrió en los pueblos, casas y familias peruanas, ocurrió en otro país, un Perú ajeno a la modernidad", señalando así, no solo la discriminación pública, sino también un sentido común generalizado y encubierto cuyos efectos fueron evidentes tanto para el hablante como para el receptor u objeto de los mismos.

Que los indígenas han sido arrinconados de la nación-Estado es un hecho bien sabido. Desde la descripción que Sarmiento hace de Buenos Aires como un enclave urbano asediado por las tierras salvajes y sus habitantes hasta los esfuerzos de Porfirio Díaz para reubicar a los problemáticos Yaqui, los indígenas exiliados por su supuesta calidad de primitivos ajenos a la sociedad, parias de la modernización y sin estatus de ciudadanos en el Estado República. La "conquista espiritual" del Nuevo Mundo por cuenta de los Españoles Católicos se fundamentó bajo la lógica de la limpieza y persecución contra el mundo judío y el musulmán discriminados con base en argumentos religiosos. El Estado secular post independentista vio la iglesia como una fortaleza de reacción y anti modernización y cambió las bases de discriminación yendo de las creencias religiosas heréticas al atraso y la resistencia a la modernización.

El patrón por el cual la herejía religiosa se conmutó en herejía contra el Estado, justificando el genocidio, es por supuesto, un fenómeno que no pertenece únicamente a Latinoamérica. En su trabajo documental acerca del campo de exterminio de Auschitz, Van Pelt y Dwork argumentan que el exterminio de los judíos articuló prejuicios que venían de siglos atrás contra los enemigos de la cristiandad con el proyecto imperial que buscaba reclamar los territorios orientales que se habían perdido con anterioridad, así como la reubicación de los alemanes en el imperio recién expandido al desplazar y exterminar a las comunidades judías (van Pelt y Dwork 1996). En Latinoamérica, el pretexto para la subyugación de los indígenas se reformuló de manera constante de acuerdo a las 
necesidades del Estado. Se libró en cientos de diferentes escenarios que fueron desde las guerras de casta de Yucatán, la campaña del desierto en la Argentina, el decomiso de los territorios Mapuches en Chile, así como en los proyectos de asimilación pacífica promovidos por los Indigenistas.

La separación indígena del grueso de la población y de las corrientes principales del Estado se decretó inmediatamente después de la conquista cuando se fundaron municipios indígenas separados, constituyendo de este modo, en palabras de Díaz Polanco, "las instituciones más importantes del dominio español" (Díaz Polanco 1997). El nacionalismo económico y cultural moderno se fundó bajo este régimen colonial de segregación indígena, lo cual trajo una clase marginal diferenciada étnicamente de modo que las poblaciones indígenas se empezaron a ver, en palabras de Carlos Iván Degregori "solo como víctimas, o solo desde su interior, con sus energías concentradas en reproducir una casi inmutable forma de vida" (Degregori 1998). Fueron así estigmatizados, convertidos en chivos expiatorios de la modernización fallida o incompleta de la nación. Una solución propuesta con frecuencia para enfrentar este problema fue la asimilación y la renuncia al idioma, a las creencias y tradiciones, como precio a pagar por su acceso a la modernidad (Mayer 1992).

La frase 'ajeno a la modernidad' es claramente el resultado de décadas e incluso siglos de sedimentación de un discurso de discriminación convertido en axioma. Aunque no se deberían mezclar los efectos de la identidad étnica y de género, la aseveración de Judith Butler con respecto al género puede aplicarse a la diferencia étnica. Ella lo refiere como un

$[\ldots]$ modo epistemológico de apropiación, medio y distanciación [...] que pertenece a una estrategia de dominación que marca el "yo" contra el "otro" lo cual se ha sedimentado a su vez a través de un proceso de repetición. (Butler 1990)

El discurso es un texto social que se aprende, se reproduce y se reitera constantemente como si se tratara de sentido común. En un artículo publicado en la web, "El sujeto del saqueo y la violación", Slavoj Žižek, al comentar los rumores de saqueo en Nueva Orleans después del desastre, escribe que,

$[\ldots]$ incluso si los reportes de violencia y saqueo prueban ser ciertos, los relatos probarán ser patológicos y racistas puesto que lo que motiva estos relatos es el prejuicio del racismo, la satisfacción que sienten quienes se atreven a decir: "ya ves, así son los negros" (Žižek 2005)

En el documento que aquí se examina, la conclusión es que "los indígenas son así, ajenos a la modernidad" y como se verá, supuestamente programados para la violencia. 
Las consecuencias devastadoras de estos discursos de sentido común salieron a flote en un famoso incidente de la guerra civil que fue puesto bajo profundo escrutinio por la Comisión de Verdad y Reconciliación. Ocurrió en enero de 1983 cuando un grupo de ocho periodistas peruanos fueron atacados y asesinados en la aldea de Uchuraccay. Al respecto se han escrito innumerables páginas, pero aquello que llama la atención es la manera en la que el prejuicio y la discriminación se validaron como verdad irrefutable. Los periodistas, quienes viajaban a Huaychao a investigar los asesinatos de unos miembros del grupo Sendero Luminoso a manos de indígenas de la zona, fueron golpeados hasta morir mientras intentaban pasar por la aldea vecina, Uchuraccay, en una región de la Sierra parcialmente controlada por Sendero. Las muertes, ocurridas en el marco de la guerra civil, no por ello pasaron desapercibidas y fueron la causa de numerosas protestas a nivel nacional.

Aunque lo ocurrido en Uchuraccay fue un incidente más en la guerra civil entre Sendero Luminoso y el ejército y la policía, tuvo una importancia extraordinaria porque las víctimas fueron periodistas a los que póstumamente se les conmemoró como los mártires de Uchuraccay, también porque la comisión realizó una investigación de los hechos bajo la dirección de Vargas Llosa, famoso novelista, intelectual público y eventual candidato presidencial y porque su reporte causó polémica. La comisión Vargas Llosa, que incluyó antropólogos, un experto legal, un lingüista (el único hablante de quechua) y un psicoanalista, llegó en helicóptero a la zona y estuvo allí por un lapso de menos de tres horas lo cual, como señalaron los críticos y la Comisión de Verdad, fue en extremo irregular. Sin embargo, Vargas Llosa emitió un reporte hábilmente escrito y posteriormente dio numerosas entrevistas y escribió artículos y textos rebatiendo la opinión de quienes criticaron su reporte inicial, textos que se publicaron después en una colección de ensayos bajo el llamativo título: "Sangre y mugre de Uchuraccay"? Las implicaciones del texto de Vargas Llosa van más allá del evento mismo y genera inquietudes acerca de las raíces de la violencia, acerca de la atrocidad y de la discriminación y eventualmente, acerca del sistema de justicia en una nación multilingüe. También genera inquietudes acerca del estatus ético de la literatura y de la naturaleza autoritaria de la ciudad letrada.

2 Mario Vargas Llosa, Contra viento y marea, vol. 3 (Barcelona: Seix Barral, 1990) incluye diez textos acerca de Uchuraccay bajo el título, "Sangre y mugre de Uchuraccay" que incluye la versión en español del ensayo publicado en The New York Times del cual el autor de este artículo realizó sus traducciones. Ver también la entrevista con Alberto Bonilla, "Después del Informe. Conversación sobre Uchuraccay", Contra viento y marea, vol 3, 150-1. 
En su reporte y entrevistas, artículos y polémicas, Vargas Llosa, una y otra vez, se representa a sí mismo como al hombre moderno y racional que debe enfrentar a ese otro ser que es ajeno. En su vívido escrito "Pesquisa en los Andes", artículo que se publicó en The New York Times, el cual encapsula el trabajo de su comisión, empieza por recrear los pensamientos y sensaciones de los periodistas en su viaje en taxi, sin ninguna premonición de peligro, y luego su caminata en arduos terrenos hacia Huaychao, una ruta que los llevaría a través de Uchuraccay. Esta parte de la narrativa se cuenta con un detallado ojo novelístico. Vargas Llosa reproduce las bromas, el momento en que se detuvieron para tomar fotografías, también describe el sitio en el que se detuvieron para desayunar, el encuentro con el guía, Juan Argumedo, con quien se reunieron en el momento en que este se encontraba cortando madera. Esta empatía con los periodistas, su preocupación por cada detalle del viaje final de estos, se encuentra en brusco contraste con la descripción que hace de los comuneros hablantes de quechua a quienes da el nombre de "iquichanos" y quienes son descritos como un grupo que se aferra a unas antiguas creencias en los apus - los dioses de las montañas. Los iquichanos que aparecen en su reporte son monolingües, desesperadamente pobres y en ocasiones violentos, especialmente si ven amenazada su forma de vida. Durante la independencia, los iquichanos fueron un movimiento rebelde que luchó de lado de los realistas y que se negó a aceptar la República. "Los pocos estudios acerca de su forma de vida", escribe, "los describen como defensores celosos de esos usos y costumbres, los cuales, aunque arcaicos, son los únicos que tienen".

Lo que resulta impactante del relato de Vargas Llosa es que, mientras las acciones de los periodistas y de los mestizos tienen sentido, las de los indígenas parecen absurdas. Entienden tan poco de las explicaciones de los esquemas de la ley, escribe:

[...] mientras les expliqué esto (que en el Perú es ilegal matar y que existen jueces y cortes que son los organismos que están a cargo de la ley) y miraba sus rostros, me sentí tan absurdo e irreal como si hubiera estado adoctrinándolos en la verdadera filosofía revolucionaria del camarada Mao traicionado por el Perro contrarrevolucionario, Den Tsiao Ping.

Vargas Llosa, de manera inequívoca, identifica elementos mágico-rituales en la matanza -las heridas "parecían seguir un patrón ritual". Los periodistas fueron enterrados boca abajo "como demonios o como quienes han pactado con el demonio". Sus tobillos estaban rotos para evitar que regresaran a vengarse. Concluye: "La violencia que observamos nos sorprende porque es anómalo ver algo así en nuestra vida cotidiana. Para los iquichanos esa violencia es la atmósfera 
en la que se mueven desde el nacimiento hasta la muerte". Solo cabe preguntarse cómo es que Vargas Llosa únicamente ve una "violencia que nos sorprende" en los asesinatos cometidos por los iquichanos siendo que la vida moderna ofrece ejemplos a diario de tiroteos a inmigrantes ilegales que cruzan las fronteras, de torturas y de bombardeo a inocentes.

En el momento en que la comisión se prepara para dejar el lugar, una "pequeña mujer" de la comunidad empieza a danzar de repente. Vargas Llosa la describe así:

Canturreaba una canción que no pudimos entender. Era una indígena pequeña como una niña pero con rostro de anciana, con los pómulos cuarteados y los labios hinchados de quien ha estado expuesto al frío de los punas. Estaba descalza, y vestía faldas coloridas, un sombrero con cintas y mientras cantaba y bailaba, nos golpeteaba las piernas lentamente con una rama de ortiga. $\dot{\mathrm{d}}^{\mathrm{N} o s}$ despedía siguiendo un antiguo ritual? ${ }_{\mathrm{C}}$ Nos maldecía por pertenecer a ese mundo de forasteros -Senderistas, periodistas-, quienes habían traído nuevos motivos de angustia y miedo a sus vidas? ${ }_{\mathrm{C}}$ Nos exorcizaba?

Vargas Llosa confiesa que el incidente lo deja perturbado porque siente como si aquello le hubiera revelado una nueva y terrible historia de su país. Nunca antes se había sentido tan triste como ante el ocaso de las amenazadoras nubes de Uchuraccay, cuando:

Vimos a esta pequeña mujer bailando y golpeteándonos con ortiga, quien parecía haber venido de un Perú muy distinto al cual yo habito, un Perú antiguo $\mathrm{y}$ arcaico que ha sobrevivido en medio de estas montañas sagradas a pesar de los siglos de olvido y adversidad. Esta frágil mujer era, sin duda, una de las personas que participó en la lapidación de los periodistas puesto que las mujeres iquichana son tan beligerantes como los hombres. (El énfasis es del autor de este artículo)

Pero ¿cuál es la diferencia entre esta llamada violencia primitiva y los castigos ejercidos por Sendero o el ejército mismo?, ¿el hecho de que los aldeanos golpearon con palos y piedras y no con pistolas y dinamita?, ¿se trata de la participación de mujeres lo que hace que este evento sea tan asombroso para Vargas Llosa? Las acciones de la mujer resultan inexplicables, sus palabras ininteligibles, pero el autor en ninguna parte sugiere que su ignorancia del quechua, una lengua hablada por miles de sus compatriotas campesinos, pueda ser parte del problema. 
Veinte años después, la Comisión de Verdad y Reconciliación contaría una verdad muy distinta, una verdad que incluiría el testimonio quechua. Se señaló que Sendero había previamente infiltrado la aldea, causando alarma y que las demandas de protección contra ataques de Sendero fueron ignoradas y continuaron siendo ignoradas por las autoridades. La Comisión de Verdad sostuvo que el miedo que los había empujado a tomar a los periodistas por Senderistas, llevándolos a matarlos, no se debió a retroceso y arcaísmo, sino que se trató de una respuesta a un peligro claro y presente traído por las propias tácticas de Sendero y la respuesta del ejército. De hecho, etnógrafos que han estado trabajando en otras comunidades han notado la constitución de estrategias de identidades comunitarias en servicio de la supervivencia de la cual la milicia campesina (rondas) formó para proteger las comunidades de ataques de Sendero, por demás, su colaboración con el ejército y la policía se constituyeron en buenos ejemplos de lo anterior (Theidon 2003).

Uchuraccay no fue nunca una comunidad que careciera de contacto con el resto del Perú. Había un colegio, una iglesia, un cementerio y un cabildo. La aldea se encuentra situada estratégicamente del centro de actividades de Sendero, miembros de la organización guerrillera coexistían en un estado de tensión con los habitantes de la aldea, lo cual llegó a su punto álgido cuando intentaron organizar un colegio para adoctrinar a las mujeres. Fue esto lo que ocasionó el levantamiento hostil de la comunidad, una hostilidad que se agravó cuando Sendero ejecutó al líder de la comunidad, Alejandro Huamán, lo cual, a su vez, llevó a que la comunidad se resistiera y asesinara con piedras y mazas de madera a cinco senderistas, meses antes de los acontecimientos de enero de 1983. La acción fue aprobada por el general Noel, comandante regional de las fuerzas armadas, quien envió en helicóptero a quince de sus miembros de las fuerzas de seguridad, conocidos como sinchis, para alentar a la comunidad a atacar a cualquier extraño que se acercara a la zona.

Cuando los periodistas llegaron a la aldea, los comuneros se negaron a escuchar sus explicaciones, asumieron que eran Senderistas y los apalearon hasta matarlos, luego enterraron rápidamente los cuerpos cerca de la plaza central. Los cuerpos del guía Juan Argumedo y de Severino Huáscar Morales, un simpatizante de Sendero, fueron mantenidos en secreto para que los sinchis no sospecharan que Sendero había estado presente en la comunidad y tomaran represalias ${ }^{3}$. La comunidad, dividida hasta entonces, decidió hacer un pacto de silencio con respecto

3 Se trataba de un temor legítimo, debido a las maneras extremas en que el ejército tomaba represalias. 
a aquellas dos muertes y reportaron las muertes de los periodistas como un acto contra el terrorismo. El uso de terrorismo como justificación para la retaliación violenta no tuvo nada que ver con un ritual arcaico sino una respuesta, errada es cierto, a una situación intolerable y completamente contemporánea. Más aún, la indiferencia de la comisión Vargas Llosa y del gobierno Balaúnde a las peticiones de la comunidad para que se les protegiera de los ataques de Sendero la sentenció a su completa extinción. En las vísperas de la masacre, ciento treinta y cinco miembros de la comunidad, de un total de 470 habitantes, fueron asesinados, la mayoría por Sendero, de manera que la comunidad se diseminó y dejó de existir. Los miembros que no perecieron en la masacre abandonaron el poblado y se vieron obligados a ocultar su identidad y paradero; algunos describieron su vida en el exilio "como una suerte de sonambulismo, hemos vivido enajenados". Muy pocos han retornado desde entonces.

La Comisión de Verdad y Reconciliación atravesó momentos muy difíciles para subrayar las peligrosas consecuencias de la distorsión y la malinterpretación que se había hecho de las acciones de la comunidad hasta el momento. Un ejemplo de ellos es que la comisión Vargas Llosa describió a los comuneros como 'iquichanos', un supuesto grupo prehispánico conocidos por su naturaleza beligerante. De hecho la reputación violenta de este grupo fue una invención de las élites del siglo XIX, no una verdad histórica. En todo caso, lo anterior fundamenta la tesis de los dos Perús -el Perú arcaico, violento e insensible al cambio, y el Perú modernopropuesta por Vargas Llosa y aparentemente, por el antropólogo en la comisión Vargas Llosa, quien concluyó que "el mejoramiento y el progreso son nociones inconcebibles para ellos", y puso en tela de juicio el que la comunidad pudiese hacer "distinciones morales, constitucionales y jurídicas (...) entre el bien y el mal". Pasaron por alto el hecho de que algunos comuneros estaban vestidos como cualquier otro peruano de la urbe y llevaban relojes de pulso, y que el $30 \%$ de la comunidad estaba alfabetizada. Una de sus numerosas demandas tenía que ver con la escolarización de la comunidad tanto en español como en quechua, puesto que sabían de las desventajas del monolingüismo; tampoco ignoraban las leyes de la constitución, dado que con frecuencia habían recurrido a la guardia civil.

Como la Comisión de Verdad señaló, la interpretación que Vargas Llosa hizo de los eventos contribuye a un paradigma que esencializa las diferencias culturales y construye la imagen de una comunidad primitiva y completamente aislada de la vida ciudadana y por tanto, de la nación. De parte de la izquierda, los periodistas tergiversaron las acciones de la comunidad y las presentaron como acciones de los sinchis, miembros de la unidad antiterrorista de la guardia civil. La malinterpretación estuvo también presente en los subsecuentes juicios a tres 
comuneros a quienes se acusó de perpetrar las masacres. Los procedimientos se tradujeron de quechua a español, pero no de español a quechua, de modo que los acusados nunca entendieron los procedimientos. Tampoco se prestó atención a ninguna de las sutilezas de la lengua quechua, la cual requiere un sufijo en cada oración para diferenciar aquello que se refiere a una declaración de ser testigo personal o de oídas (Mayer 1992). Los comuneros fueron sentenciados en 1987 (uno murió en prisión y dos fueron liberados tiempo después).

Lo que llama la atención de este incidente es la convicción de Vargas Llosa de que él representa la voz de la razón y del sentido común. Y pese a no hablar quechua y a tener poco conocimiento de las tierras altas de su país, después del incidente elaboró su tesis de los dos Perús en sus novelas, en docenas de artículos y en entrevistas, e incluso en su crítica literaria. Cuando se refiere al quechua en su novela Muerte en los Andes, publicada en 1993, para Lituma, protagonista de la historia, la lengua suena "como música salvaje". Cierto que el personaje ficcional, Lituma, no debe confundirse con el propio Vargas Llosa, pero en ninguna parte de sus escritos existe sugerencia alguna de que en un país plurilingüe como el Perú debe ser importante aprender quechua u otra lengua indígena.

En la novela Muerte en los Andes, Lituma, un personaje que primero aparece en la novela La Casa Verde, se ha convertido en un guarda civil del norte honesto y escrupuloso, y ha sido enviado a un área que no conoce y con la cual no puede identificarse. Enfrentado a una serie de desapariciones inexplicables a mitad de una guerra civil, decide atribuir la matanza no a la guerra, sino a un ritual antropófago. El canibalismo es descrito como una suerte de ritual de sacrificio dionisiaco liderado por mujeres. "Solo las mujeres fueron a cazarlo en la última noche de la fiesta" (Vargas Llosa 1996). La aparente violencia irracional de Sendero es, en esta novela, puesta al mismo nivel e incluso superada en horror por los rituales sangrientos del otro Perú.

A simple vista se puede notar que este llamado pasado arcaico y violento existe como un subconsciente en varias de las novelas del boom. En el cuento de Carlos Fuentes, "Chac Mool", por ejemplo, el dios azteca de la lluvia viene a la vida y en "La noche boca arriba", de Julio Cortázar, el ajeno pasado azteca con sus cultos de sacrificios se levanta para devorar al hombre moderno que se convierte en una víctima sacrificial. Pero en Vargas Llosa el pasado arcaico asume no solo una forma ficcional, sino que también se convierte en filosofía política, una filosofía que puede ser descrita en palabras de Víctor Vich como "autoritaria" y que cierra toda puerta al diálogo (Vich 2002). Del mismo modo en que Octavio Paz creyó que el moderno Estado mexicano realizaba una recreación de la violencia primitiva de los aztecas, Vargas Llosa hace que uno de los personajes de Muerte en los Andes se pregunte 
si "lo que está pasando en Perú no es acaso una resurrección de esa violencia ya enterrada. Como si hubiera estado escondida en algún lugar y, de pronto, por alguna razón, hubiera resurgido". Lo cual es una perspectiva compartida por algunos militares del momento. "Siempre ha habido violencia en estas montañas, desde el tiempo de los incas y los españoles", afirmó el comandante Vasquez quien además terminaba: "CCómo podemos hacer la paz con estos indios?" .

Lo que está detrás de esta actitud es una filosofía política que Vargas Llosa presenta bajo la forma de crítica literaria en su libro La utopía arcaica acerca del escritor Peruano José María Arguedas. Arguedas, un escritor perseguido, hablante del quechua y del español, quien vivió y viajó a lo largo y ancho de todo el Perú andino y pasó toda su vida escribiendo acerca de las culturas indígenas, su persistencia y transformaciones, es cruelmente caricaturizado por Sendero como un nacionalista exacerbado que llevaba un bigote a lo Hitler, que también fue ridiculizado por la derecha como un indigenista romántico. Como folclorista, Arguedas recolectó evidencia de un culto popular alrededor de la figura de Inkarri, el líder Inca cuyo cuerpo decapitado, se creía, volvería a estar completo de nuevo y retornaría algún día. Vargas Llosa argumenta

[...] el dios mutilado que fue rehecho en su refugio subterráneo era emblema del deseo de resurrección de esa utopía arcaica a la que él [Arguedas] ha sido siempre instintivamente fiel, incluso cuando su razón e inteligencia le decía que la modernización de la región era inevitable e indispensable". (Vargas Llosa 132) $)^{5}$

Veinte años después del suicidio de Arguedas en 1969, posterior a la devastación de la guerra civil y muchos años después del incidente Uchuraccay, Vargas Llosa dedicó un libro de más de 300 páginas a este escritor hacia el cual mostraba sentimientos, en el mejor de los casos, ambiguos. Arguedas escribió, dice, solo una novela hermosa, Ríos profundos; el resto de su trabajo "es una serie parcial de éxitos y fracasos". A pesar de esta tibia introducción, es claro que la crítica literaria es solo una distracción de un proyecto mucho más amplio -el de destruir aquello que Vargas Llosa entiende como la errada creencia de Arguedas en el colectivismo y su oposición a una forma particular de modernización-, siendo claro que Arguedas postuló más inquietudes que respuestas. Es, también, muy

4 Citado como epígrafe por Kimberley Theidon, en la version inglesa de su ensayo, "'How we learned to kill our brother': Memory, morality and reconciliation in Peru", disponible en línea en: http://www.celat.ulaval.ca/histoire.memoire/histoire/cape1/theidon.html

5 Para un punto de vista distinto ver a Alberto Flores Galindo, Europa y el país de los Incas. La utopía andina (Lima: Instituto de Apoyo Agrario, 1986). 
difícil no preguntarse ¿por qué Vargas Llosa, un autor que siempre defendió públicamente a la literatura como un desafío a la realidad, critica a Arguedas precisamente por ese trabajo que no se corresponde con la realidad? $\dot{\mathrm{c}}$ Acaso la respuesta está en la aprensión con que confronta a ese extraño nuevo Perú en 1999, que lo rechazó como candidato a la presidencia a favor del peruano-japonés Fujimori, un presidente que ató la modernización a la policía estatal? d $\mathrm{O}$ es que necesitaba describir el ideal colectivo como retrógrado para poder proponer al individuo autónomo de la filosofía liberal bajo una luz más positiva?

La filosofía de Vargas Llosa, extraída de La sociedad abierta y sus enemigos de Karl Popper, es descrita como racional y completamente opuesta al mundo mágico religioso que promulga, es el de Arguedas. Popper elaboró su teoría como una crítica al totalitarismo, cuyas premisas halló en Platón y arguyó que nos enfrentamos a una elección,

$[\ldots]$ entre depositar nuestra fe en la razón y en el ser humano individual o en depositar nuestra fe en las facultades místicas del hombre por medio de las cuales se encuentra unido a la colectividad; y que esta elección es, al mismo tiempo, una elección entre una actitud que reconozca la unidad de la humanidad y una actitud que separa a los hombres entre amigos y enemigos, entre amos y esclavos. (Popper 1952)

Siguiendo a Popper, Vargas Llosa desestima lo mágico religioso como primitivo y supeditado a lo colectivo; es el reemplazo de lo mágico por el pensamiento científico lo que permitió la disolución de la realidad colectiva humana de la horda y de la tribu en una comunidad libre dominada por el individuo (Vargas Llosa 186). Extrañamente, las creencias mágico-religiosas se le atribuyen únicamente a los indígenas a pesar del hecho de que la religión es generalizada en las sociedades contemporáneas, no menos en los Estados Unidos donde millones siguen esperando el apocalipsis. En un brillante ensayo acerca de la "cholificación" del Perú,José Guillermo Nugent llama a esto "contramodernidad" y escribe que va más allá de la exclusión. "Se atribuye de manera agresiva una identidad arcaica a ciertos actores sociales y se asegura la continuidad y reproducción de este tipo de discurso" (Nugent 73). Los indios son así, atrasados y violentos.

La consecuencia de esta perspectiva que ve el progreso como un desarrollo lineal que parte de comunidades vinculadas por las creencias mágicas hasta la sociedad moderna es que requiere la desaparición del progreso indígena. El crítico mexicano Héctor Díaz Polanco emplea el término etnofagia para describir la eliminación de la diferencia indígena, "que depende de los efectos de asimilación que desempeñan múltiples fuerzas de la cultura nacional dominante" (Díaz 
Polanco 59). Sin importar si la formulación es en términos del progreso, del desarrollo, de la modernidad o incluso de la revolución, tales soluciones derivan de una formación discursiva que homogeniza y simplifica la identidad indígena sin tomar en cuenta la sedimentación histórica de la discriminación, lo cual ha sido subrayado por la Comisión de Reconciliación y Verdad. Entre sus numerosas recomendaciones hay propuestas que buscan reeducar a la ciudadanía.

También las conclusiones de la la Comisión de Reconciliación y Verdad han generado "debates acerca de los derechos indígenas, la impunidad, la reparación y la responsabilidad del Estado" (García 54). Es la propuesta de no menos que un nuevo "pacto entre el Estado y la sociedad peruana, y entre los miembros de esa sociedad", empleando términos que no se escuchan con frecuencia en el discurso político, términos como: perdón, responsabilidad y justicia. En un compromiso serio con las prácticas democráticas, la comisión mantuvo audiencias públicas en las que se dio voz a todo tipo de opiniones, incluyendo aquellas opiniones formuladas en lenguas tradicionalmente excluidas. En su determinación de construir una nueva historia, se buscó la reunión de comunidades divididas por la guerra y se buscó también, la constitución de un país que se reconociera, con convicción, como una nación multiétnica, pluricultural y multilingüe.

En todo caso, como el historiador Greg Grandin señala, las Comisiones de Verdad son cuerpos contradictorios porque "generan esperanza en la justicia simbolizada por los juicios de Nuremberg a la vez que operan dentro de las limitadas condiciones políticas que existen en la mayoría de Estados de la era post-guerra fría" (Grandin 18). Mientras que la comisión peruana tuvo que vencer grandes dificultades para publicitar sus hallazgos y confrontar a la sociedad peruana con su pasado violento, la sociedad a la cual investigó ya se encontraba en la mitad de un intenso proceso de cambio en el cual la discriminación era la consecuencia. De hecho, en las páginas finales de La utopía arcaica, Vargas Llosa reconoce estos cambios y celebra la conversión de los indígenas en cholos urbanos y subraya que la emergencia de un nuevo Perú informal elimina el sueño utópico de Arguedas para siempre. "Gracias a estos ex indios, cholos, negros, mulatos y asiáticos", escribe, "se ha desarrollado, por primera vez en nuestra historia, un capitalismo popular y un mercado libre en el Perú".

En lo que todos los peruanos pueden ahora estar de acuerdo es que,

[...] el Perú que está en plena formación no se parecerá en nada al resucitado Tahuantinsuyu; no será una sociedad colectiva de naturaleza étnica, tampoco un país en guerra con valores burgueses de comercio y de producción de riqueza, ni un país cerrado a un mundo exterior de intercambio en defensa de su identidad inmutable. 
Los indígenas son identificados con ideales socialistas desacreditados para poder glorificar otra figura fantástica: el individuo autónomo del capitalismo ${ }^{6}$. Pero la discriminación no desaparece. Los indígenas urbanos generan temor hacia sus posibles actos violentos y desintegración social cuyos índices, de acuerdo a Guillermo Nugent, pueden verse en el característico paisaje urbano de Lima, de casas aseguradas tras alambre de púas y rejas de hierro tras las cuales habita "el individuo autónomo" que Vargas Llosa enaltece (Nugent 89-9o).

Esta sesgada tesis de final-de-historia no se mantuvo por mucho tiempo. Lo que ha marcado a la reciente sociedad peruana y de hecho a la sociedad andina en general, ha sido la emergencia de una fuerza política indígena que ahora interviene -a menudo de manera efectiva- en la cultura y la política del continente, generando, por lo menos para Vargas Llosa, un nuevo espectro, el espectro del racismo indígena que se identifica con Evo Morales en Bolivia, con Hugo Chávez en Venezuela, y con el candidato presidencial Ollanta Humala en Perú. A la advertencia que hace Vargas Llosa acerca de un nuevo racismo, de indios contra blancos, se le dio amplio cubrimiento en Europa y América Latina. Vargas Llosa arguye que la discriminación en América Latina no es racial sino cultural y económica, en consecuencia, de manera irónica señaló que Evo Morales no es un indígena, sino un "criollo" que es "astuto como una ardilla, un escalador social, y un busca pleitos (latero)".

Sin tomar en consideración su propio prontuario de prejuicio racial, Vargas Llosa se refiere a Morales, Chávez y Humala indiscriminadamente como "caudillos barbaros" quienes están "confiriendo legitimidad a una nueva forma de racismo" ". Lo que Vargas Llosa no advierte empero, es que el fracaso del neoliberalismo por el cual abogó tanto ha generado la búsqueda de nuevas alternativas que están tomando numerosas formas, incluyendo el etnonacionalismo. El hecho de que los indígenas, lejos de ser unos verdaderos actores ajenos a la modernidad, esté utilizando la modernidad, sus tecnologías, sus espacios, y sus posibilidades políticas (e incluso estén ganando elecciones) debe ser especialmente molesto para él, teniendo en cuenta su poco disimulada rabia y consternación, lo cual se ha visto reflejado en afirmaciones como las que siguen, en las cuales describe el etnonacionalismo como un "elemento profundamente perturbador que recurre a

6 Charles Hale nos lo advierte, "el núcleo del proyecto cultural del neoliberalismo no es el individualismo radical, sino la creación de sujetos que se autogobiernen de acuerdo con la lógica del capitalismo globalizado" (Hale 17).

7 "Raza, botas y nacionalismo" fue publicado en El País en enero 15 de 2006 y ha sido publicitado ampliamente. Existe una version en ingles en http://www.vcrisis.com 
los más bajos instintos, los peores instintos del individuo, como la desconfianza hacia los demás, hacia cualquiera que sea diferente" (Lucas 2003).

Tales generalizaciones tan crudas no pueden, de ninguna manera, contribuir a un entendimiento del veloz cambio de panorama; tampoco, representar el alcance de las tensiones sociales que están en juego. Un desarrollo paradójico de lo anterior es que los pueblos de la Sierra que no se consideran a sí mismos como "indígenas" sino runasimi o campesinos, han sido reconocidos como "indígenas" por el presidente Toledo, quien, en su posesión, firmó la declaración de Machu Picchu en apoyo a los derechos indígenas. El gobierno de Toledo también creó la Comisión Nacional de los pueblos Andinos, Amazónicos y Afroperuanos (CONAPA), al principio bajo el liderazgo controversial de la esposa del presidente, Eliane Karp (García 170-171). Semejante multiculturalismo oficial abre espacios al activismo político pero tiene sus límites (Hale 18-19).

El legado de discriminación también se revela en las nuevas identidades adoptadas por los pueblos de la Sierra, particularmente cuando estos inmigran a las ciudades, identidades que incluyen "indio mestizo" y "cholo". Algunos pueblos de la Sierra han empezado a identificarse como "altoandinos", evadiendo de esta manera las categorías estigmatizadas de indio o chuto. En lo concerniente a este texto, las respuestas más reveladoras frente a la historia de la discriminación surgen en las tensiones sobre la lengua que han sido descritas por María Elena García en su libro acerca de la educación bilingüe. En reuniones con comunidades de la Sierra, los padres han insistido con frecuencia en la prioridad que debe dársele a la alfabetización en español, puesto que es una "vergüenza" ser monolingüe en solo quechua, lo cual demuestra qué tan profunda está enquistada la discriminación en la diferencia lingüística y el analfabetismo.

Es precisamente la negligencia histórica hacia la educación indígena la que ha entorpecido el desarrollo del quechua y que también ha contribuido al aislamiento de los hablantes monolingües, especialmente el de las mujeres (García 96-104). Pero la "vergüenza" de hablar quechua está siendo también superada de una manera bastante innovadora por los intelectuales indígenas quienes están determinados a establecer el quechua como lengua escrita capaz de generar literatura e ideas, implementando, de esta manera, una de las ambiciones más preciadas por José María Arguedas. A la par de otros muchos grupos indígenas -Mapuches, Zapotecas, Aymaras- los intelectuales quechuas ahora emplean las tecnologías modernas para promover la escritura en sus comunidades, de esta manera ya no

8 Ver los datos que aparecen en Kimberly Theidon (2003). Ver también Marisol de la Cadena, (2001). Nugent (1992) también desarrolla los términos "indio urbano" y "cholo". 
estarán "ciegos" (García 146-148). Estos esfuerzos tienden a caer bajo el radar de la política nacional, pero se trata, tal vez, de la única esperanza que tiene el Perú pluricultural concebido por la Comisión de Verdad y Reconciliación.

\section{Obras citadas}

Butler,Judith. Gender Trouble. Feminism and the Subversion

of Identity. Nueva York: Routledge, 1990.

de la Cadena, Marisol. "Reconstructing Race: Racism, Culture and Mestizaje".

Latin America, NACLA Report on the Americas 34.6 (2001, mayo-junio): 16-23.

Degregori, Carlos Iván. "Movimientos étnicos, democracia y nación en Perú y Bolivia". Ed. Claudia Dery. La construcción de la nación y representación en México, Guatemala, Perú, Ecuador y Bolivia. Guatemala: Flacso, 1998.

Díaz Polanco, Héctor. Indigenous Peoples in Latin

America. Boulder: Westview Press, 1997.

Flores Galindo, Alberto. Europa y el país de los Incas. La utopía andina. Lima: Instituto de Apoyo Agrario, 1986.

García, María Elena. Making Indigenous Citizens. Identity, Development and Multicultural Activism in Peru. Stanford: Stanford University Press, 2005.

Grandin, Greg. "The Instruction o Great Catastrophe: Truth Commissions, National History, and State Formation in Argentina, Chile and Guatemala". American Historical Review 110.1 (2005, febrero).

Hale, Charles. "Rethinking Indigenous Politics in the Era of the "Indio Permitido"'. NACLA Report on the Americas 38.2 (2004, sept-oct): 15-22.

Lucas, Kintto. "Indigenous Leaders Angry at Vargas Llosa's Remarks". Stereotype of the Month Entry (2003, 11 de diciembre). Disponible en http://www.bluecorncomics.com/stype3b6.htm

Mayer, Enrique. "Peru in Deep Trouble. Mario Vargas Llosa's Inquest in the Andes Reexamined". Cultural Anthropology 6.4 (1992).

Nugent, José Guillermo. El laberinto de la choledad. Lima: Fundación Friedrich Ebert, 1992.

Popper, Karl. The Open Society and its Enemies, vol. 2.

Nueva York: Routledge, 2nd edition, 1952.

van Pelt, Robert Jan y Denorah Dwork. Auschwitz: 1270

to the Present. Nueva York: Norton, 1996.

Vargas Llosa, Mario. Contra viento y marea, vol. 3. Barcelona: Seix Barral, 1990.

- La utopía arcaica. Fosé María Arguedas y las ficciones del indigenismo. México: Fondo de Cultura Económica, 1996.

- . Death in the Andes. Nueva York: Farrar, Straus and Giroux, 1996. 
Vargas Llosa, Mario y Alberto Bonilla, "Después del Informe. Conversación sobre Uchuraccay". Contra viento y marea 3 (1990): 150-151.

Theidon, Kimberley. "'How We Learned to Kill Our Brother': Memory, Morality and Reconciliation in Peru". Bulletin de l'Institut Français d'Etudes Andines 29.3 (2000): 539-554. Disponible en http:// www.ifeanet.org/publicaciones/boletines/29(3)/539.pdf

— . "Entre prójimos. Violencia y Reconciliación en el Perú". Ideele. Revista del Instituto de Defensa Legal 157 (2003, sept): 91- 96.

- . "Disarming the Subject. Remembering War and Imagining Citizenship in Peru". Cultural Critique 54 (spring 2003): 80.

Vich, Víctor. "Lituma en los libros. El caníbal es el otro". El caníbal es el otro. Violencia y cultura en el Perú contemporáneo. Lima: Instituto de Estudios Peruanos, 2002. 56-75.

Žižek, Slavoj. "The Subject Supposed to Loot and Rape". These Times (2005, octubre 20). Disponible en línea: http:www.inthesetimes.com/site/main/article/236. 